\title{
Helicobacter pylori: Basic mechanisms to clinical cure
}

\author{
ABR THOMSON MD PHD FRCPC FACP FRS FACC, CN WILLIAMS MD FRCPC
}

\begin{abstract}
ABR Thomson, CN Williams. Helicobacter pylori: Basic mechanisms to clinical cure. Can J Gastroenterol 1995;9(2):91-95. Since its rediscovery 10 years ago, Helicobacter pylori has reshaped our thinking about the course of peptic ulcer disease. Our approach to the patient with a duodenal ulcer has become one of attempting eradication therapy at the time of first diagnosis, in the hope of curing the ulcer disease. Gastric and duodenal ulceration are only two of the manifestations of this chronic antral infection; other complications of $\mathrm{H}$ pylori include gastritis, gastric cancer and possible maltomas. Therapy of $H$ pylori infection is complicated and involves dual therapy with an antibiotic plus a protein pump inhibitor, such as omeprazole $20 \mathrm{mg}$ bid plus amoxicillin $1 \mathrm{~g}$ bid for two weeks, triple or quadruple therapy with bismuth, two antibiotics and an $\mathrm{H}_{2}$-receptor antagonist. Vaccination against $H$ pylori is on the far horizon.
\end{abstract}

Key Words: Chronic antral gastritis, Duodenal and gastric ulcer disease, Eradication therapy

\section{Helicobacter pylori : Mécanismes fondamentaux de la guérison clinique}

RÉSUMÉ : Depuis sa découverte, il y a dix ans, Helicobacter pylori a modifié notre perception de l'évolution de l'ulcère gastroduodénal. Notre approche du patient atteint d'un ulcère gastroduodénal vise l'éradication au moment du diagnostic en vue de guérir la maladie ulcéreuse. Les ulcérations gastrique et duodénale ne sont que deux manifestations de cette infection antrale chronique; parmi les autres complications de l'infection à $H$ pylori, notons la gastrite, le cancer de l'estomac et de possibles maltomes. Le traitement de l'infection à $H$ pylori est complexe et suppose une double thérapie par antibiotique et inhibiteur de la pompe à protons, comme l'oméprazole à raison de $20 \mathrm{mg}$ b.i.d., plus amoxicilline $1 \mathrm{~g}$ b.i.d. durant deux semaines, un triple voire quadruple thérapie avec bismuth, deux antibiotiques et un anti- $\mathrm{H}_{2}$. La vaccination contre $\mathrm{H}$ pylori se profile à peine à l'horizon.

This review is based on presentations from an international symposium entitled 'Helicobacter pylori: Basic mechanisms to clinical cure', sponsored by Interfalk-Axcan Pharm, Ameilia Island, Florida, USA, November 3-6, 1993

Division of Gastroenterology, Dalhousie University, Halifax, Nova Scotia

Correspondence and reprints: Dr ABR Thomson, Division of Gastroenterology, University of Alberta, 519 Robert Newton Research Building, Edmonton T6G 2C2. Telephone (403) 492-6490, Fax (403) 492-7964

Received for publication January 6, 1994. Accepted July 25, 1994
$\mathrm{R}$ APPIN IN 1881 AND BIZZOZERO IN 1893 are credited with the first observations of gastric spiral-shaped bacteria in animals. It was not until the isolation of Helicobacter pylori from the inflamed stomach of humans that serious study of this genus began. H pylori has a causal role in gastritis, duodenal ulcer, probably gastric ulcer, and gastric adenocarcinoma and lymphoma, but fulfils Koch's postulates for gastritis only. Animal models are needed to study the pathogenesis of this organism; H pylori will affect germ-free pigs, dogs, perhaps nude mice, as well as nonhuman primates and barriermaintained pigs (1).

\section{H PYLORI GENOME}

There is extraordinary diversity in the $H$ pylori genome, and recently introduced polymerase chain reaction (PCR) typing has extended this heterogeneity (2). There are numerous unproven theories of the genomic diversity, such as mutation or natural competence for transformation. Molecular fingerprinting should prove useful to determine the nature of $\mathrm{H}$ pylori spread and to distinguish between recurrence or reinfection. As anticipated, clusters of strains of $H$ pylori have been identified within families.

$H$ pylori strains from ulcer patients are different from those from asymptomatic individuals (3). The presence of 
an $\mathrm{H}$ pylori $128 \mathrm{~K}$ protein cytotoxin associated gene A (cagA gene) may be a marker of enhanced probability of development of ulcer disease. This heterogeneity may have implications for the pathogenic properties of the strains, with the possibility that some will cause ulceration and some will cause metaplasia. This heterogeneity also has important implications with regards to the possible development of vaccination against $H$ pylori infection.

\section{PATHOGENESIS OF MUCOSAL DAMAGE}

Adhesion: $H$ pylori urease, a $550 \mathrm{kDa}$ multimeric enzyme, catalyzes the local hydrolyzes of urea to ammonia and carbon dioxide, resulting in a local $\mathrm{pH}$ increase in the environment around the bacteria at the endothelial surface. Urease comprises two subunits and has a $K_{\mathrm{m}}$ for urea of $170 \mathrm{mM}$, well suited for the urea concentrations in the stomach (4 mM) or blood (1.7 to $3.4 \mathrm{mM}$ ). $H$ pylori urease serves as the basis for urease and urea breath tests. The urease protein is encoded by two subunit genes, ure $\mathrm{A}$ and ure $\mathrm{D}$. These urease genes can be amplified by PCR and digested with a restriction endonuclease HaeIII, and thereby may be used for differentiation of strains. Urease is critical for $\mathrm{H}$ pylori colonization of the human gastric mucosa, and interference with urease activity may provide a suitable target for new therapeutic agents (4). There is no leader sequence on $H$ pylori urease sequence, so it is unknown how the urease gets to the surface of the organism.

It also is unknown why urease inhibitors prevent colonization but do not destroy $H$ pylori already on the mucosal surface. In addition to urease activity, there are other colonization factors, and much attention has focused on 'adhesion'. Adhesion of pathogenic bacteria to mucosal surfaces promotes disease by increasing colonization of the infected host, by promoting delivery of bacterial toxins and by facilitating entry of invasive pathogens into the cell cytoplasm (5). Adhesion is also not essential for colonization but may be relevant to ulceration (6).
How does $\mathrm{H}$ pylori infection cause mucosal damage? Ammonia produced by $H$ pylori may have a cytopathic effect on the epithelial cell and may change the chemical properties of the mucous layer (7). Ammonia is more damaging to the gastric mucosa than either hydrochloric acid or ethanol, and depletion of mucosal protective nonprotein sulfhydryl groups (such as glutathione) may precede the development of hemorrhagic mucosal lesions (8). Pretreatment with sulfhydryl drugs offers gastroprotection, suggesting that this type of injury may play a role in the pathogenesis of ammonia- and $\mathrm{H}$ pylori-induced gastric injury.

Hydrophobicity of the gastric mucosa is reduced in the presence of H pylori infection (9), similar to the reduced hydrophobicity of the gastric mucosa in patients with duodenal (DU) and gastric ulcer (GU), and the reduced hydrophobicity of the duodenal mucosa of DU patients. Eradication of $H$ pylori causes a reversal to normal in this defect in hydrophobicity.

$H$ pylori infection initially results in acute neutrophilic gastritis characterized by polymorphonuclear neutrophil (PMN) infiltration and severe epithelial degeneration. This may resolve spontaneously or may progress to active chronic gastritis with surface epithelial degeneration, acute and chronic inflammatory cell infiltration, atrophy and intestinal metaplasia (10). Severity of epithelial degeneration is correlated with the presence of $\mathrm{H}$ pylori. Degeneration is manifest as mucin depletion and cuboidal change in the surface epithelium, which rapidly recovers after elimination of $H$ pylori. It is only when atrophy becomes severe that $H$ pylori positivity declines and with it a loss of inflammatory cells, giving rise to the quiescent or 'end-stage' chronic gastritis.

$\mathrm{H}$ pylori synthesizes and secretes chemotactic factor(s) which may induce neutrophil activation and production of toxic oxygen radical $(11,12)$. It is not known why recruited PMN do not migrate across the gastric mucosa and engulf and destroy $\mathrm{H}$ pylori in its ecological niche. It is possible that PMN move into the mu- cous space and then traffic back into the mucosa, although there is no experimental proof (13).

Bacterial lipopolysaccharide products induce inflammation and may be a trigger for natural immunity (14). An analogue of the chaperoning cpn60 family of heat shock proteins have been identified in $H$ pylori, referred to as Hp54K (15). Hp54K co-purifies with urease by size exclusion chromatography. Interleukin (IL)-1 is a potent and rapid-acting inhibitor of release of histamine and platelet-activating factor, and this effect is mediated by nitric oxide.

H pylori contains alcohol dehydrogenase and produces acetaldehyde but has no aldehyde dehydrogenase activity. Actetaldhyde is a highly reactive substance and forms adducts with cellular protein, which may be immunogenic and induce antibody formation (16).

Immune function: Cytotoxicity is associated with the presence of an immunogenic high molecular weight protein (120 to $130 \mathrm{kDa}$ ), which shows some size heterogeneity (17). The cagA gene encodes for a protein with cytotoxic activity. Both mucosal and systemic immune recognition of the cagA gene product are increased in patients with peptic ulcer disease or with gastric adenocarcinoma compared with patients with $H$ pylori-associated chronic gastritis. This suggests that the cytotoxin/ cagA-positive strains of $H$ pylori are more pathogenic.

The epithelium may initiate immune/ inflammatory responses to infection that may be deleterious to the host. An infected gastric epithelial cell line infected with $H$ pylori increases IL-8 specific mRNA as well immunoreactive IL-8 (18), and it is speculated that failure of local immunity may lead to an increased release of the cytokines. $\mathrm{H}$ pylori products stimulate monocyte and neutrophils to produce increased levels of reactive oxygen intermediates with potent cytotoxic activity (19). The role of the mast cell in modulating mucosal defence and injury in $H$ pylori-associated gastritis has yet to be delineated (20).

$\mathrm{H}$ pylori colonization of the gastric 
antrum induces recruitment of B lymphocytes into the adjacent mucosa and production of local and systemic antibodies. It is unknown why the local antibody response fails to clear $\mathrm{H}$ pylori infection (21). Although mucosal $\mathrm{T}$ cells express self-reactive $T$ cell receptor, their reactivity is controlled by mechanisms that regulate local tolerance and such mechanisms may downregulate the response to $\mathrm{H}$ pylori in the gastric mucosa (22).

Acid and peptides: There is a threefold increase in acid response to infusion of gastrin-releasing peptide in $H$ pylori-positive healthy volunteers compared with healthy $\mathrm{H}$ pylori-negative volunteers. The sixfold increase in acid response in DU patients has been explained by the combination of $\mathrm{H}$ pyloriinduced hypergastrinemia and an exaggerated acid response to stimulation by gastrin (23). Following eradication of $H$ pylori infection, the exaggerated gastrin response is lost within one month and the exaggerated acid response is lost within one year. H pylori increases fasting and postprandial gastrin, but acid secretion is only increased during fasting and when the luminal $\mathrm{pH}$ is low in patients with active DU ulcers. Interestingly, eradication of $\mathrm{H}$ pylori decreases meal-stimulated gastrin levels but not basal acid output (24). Prolonged hypergastrinemia may contribute to the increased parietal cell mass characteristically present in DU patients or may be due to a compensator response to decreased parietal cells.

With $H$ pylori infection the median somatostatin RNA/rRNA rises $50 \%$ in the duodenal bulb and $100 \%$ in the gastric antrum, suggesting decreased expression of mucosal somatostatin mRNA (25).

Acute $H$ pylori infection may also give rise to 'epidemic hypochlorhydria' (26) due to contamination of the gastroscope or nasogastric tubes. $\mathrm{H}$ pylori produces at least two inhibitors of acid secretion. These observations can be reconciled with the fact that $H$ pylori and DU disease are associated with normal or increased acid secretion by conceptualizing that the hypochlordydria/ achlorhydria is an early event in the natural history of infection and that ul- cer disease occurs later, when the organism expresses few or none of the inhibitors.

Sensitivity to inflammation-induced disruption of antral mucosal nerves may contribute to the hormonal disturbances and pathogenesis of active chronic gastritis and peptic ulcer disease (27).

Acute infection with $\mathrm{H}$ pylori reduces the secretion of vitamin $\mathrm{C}$ whereas eradication reverses the lowered luminal concentration (28). Giving ascorbic acid by mouth may shift the conversion of nitrite from nitrous oxide to $\mathrm{N}$-nitrosamine.

\section{PATHOLOGY}

Gastritis: $H$ pylori infection occurs in 75 to $90 \%$ of subjects with antral gastritis. Severe erosive duodenitis is also associated with a high prevalence of $H$ pylori infection. However, there is no correlation between the macroscopic findings at endoscopy (erythema, edema or erosions) and the presence of $H$ pylori infection.

In chronic active type $\mathrm{B}$ gastritis associated with $H$ pylori infection the nature of the immune response remains obscure (29). CD4 mucosal lymphocytes expressed in the activation marker CD25 selectively respond to $\mathrm{H}$ pylori localized in the antral mucosa. Heat shock proteins selectively stimulate $\tau \delta \mathrm{T}$ cells in vitro, and these cells have been demonstrated in the mucosal lesions of $H$ pylori-infected patients. A persistent immune response relating to chronic active type B gastritis may be due to the ongoing increased expression of either microbial or autologous heat shock protein.

While $H$ pylori may cause chronic atrophic gastritis, it does not necessarily cause intestinal metaplasia, and the linear theory of chronic atrophic gastritis leading to intestinal metaplasia needs to be rethought (30); one needs to consider the possibility that there is a missing link in the development of intestinal metaplasia. The endoscopic finding of giant folds in the body and the fundus of the stomach is associated with $H$ pylori gastritis, and the giant folds disappear with eradication of H pylori (31).
Ulceration: $\mathrm{H}$ pylori is a major factor in the etiology of peptic ulcer disease, with chronic DU disease subjects infected in at least of $85 \%$ of cases. Evidence in favour of a role in peptic ulcer disease also relates to a higher rate of ulcer healing with suppression/eradication of $\mathrm{H}$ pylori and the marked diminution in ulcer relapse following long term eradication of H pylori (32). H pylori-associated gastritis may be nonatrophic (diffuse antral gastritis) or atrophic (multifocal atrophic gastritis) (33). Antioxidant micronutrients may be protective for multifocal but not for diffuse antral gastritis.

In chronic ulceration of the gastrointestinal mucosa, including peptic ulcer disease, a cell lineage develops that expresses epidermal growth factor, lysozyme and trefoil peptides. These ulcer-associated cell lineages may have a role in regeneration and repair (34).

$\mathrm{H}$ pylori infection is also associated with GU disease (35). These ulcers are located throughout the stomach, except in the prepyloric areas. Eradication of $\mathrm{H}$ pylori may accelerate $\mathrm{GU}$ healing and reduce relapse rate.

$H$ pylori infection occurs in patients with GU or DU in association with the use of nonsteroidal anti-inflammatory drugs (NSAIDs), but the acute or chronic use of NSAIDs does not give rise to an increased prevalence of $H$ pylori (36). Also, $H$ pylori infection does not increase the damage from NSAIDs. The prevalence of $H$ pylori is not increased in patients with gastroesophageal reflux disease, pernicious anemia or Zollinger-Ellison syndrome.

Cancer: Between 50 and $100 \%$ of patients with gastric adenocarcinoma have $H$ pylori, and those subjects in whom $\mathrm{H}$ pylori is not established on serology PCR methods may demonstrate the presence of $H$ pylori in the mucosa. Bacterial colonization from the stomach may be lost with the precancerous conditions chronic atrophic gastritis and intestinal metaplasia, so that the positive association between gastric adenocarcinoma and $\mathrm{H}$ pylori infection may be even greater than that risk (37). The odds ratio (relative risk) of gastric adenocarcinoma in $\mathrm{H}$ pylori-positive versus -negative individuals varies from 
2.8 to 6.0 , with this variation due to the time difference between blood sampling for serological diagnosis of $\mathrm{H}$ pylori and the subsequent diagnosis of cancer. This raises the possibility of preventing gastric cancer in the future by eradication of $\mathrm{H}$ pylori.

The 1975 Correa hypothesis suggesting a role for bacterial overgrowth in the development of gastric cancer has not been confirmed, with no clear demonstration of increased $\mathrm{N}$-nitrosocompounds when there is reduced luminal acidity, bacterial overgrowth or increased luminal nitrite (38).

PCR techniques may be useful to establish the epidemiology of $H$ pylori-associated gastric cancer (39). PCR may be used to determine the presence of $\mathrm{H}$ pylori even before it is seen on biopsy or in seronegative patients who develop gastric cancer.

Lymphoid follicles are present in about half of patients with $H$ pylori-gastritis, and mucosa-associated lymphoid tissue (MALT)-associated lymphoma, but not nodal lymphoma, is also associated with $H$ pylori. In 12 patients with MALT lymphoma treated with $H$ pylori eradication therapy, MALT lymphoma disappeared (40). MALT-gastric lymphoma is associated with $H$ pylori infection, and there is a 1.89 odds ratio in patients with colonic adenoma versus controls.

\section{PREVALENCE}

There are differences in the prevalence of $H$ pylori infection between developing countries and developed countries, the most striking being the higher incidence of infection in young children in developing countries. Interestingly, the incidence and prevalence of $\mathrm{H}$ pylori gastritis may be decreasing in Finland (41). Density of living is strongly associated with a higher prevalence of infection and there may be intrafamilial transmission from parent to child. H pylori has been detected from feces, suggesting a possible fecaloral route of transmission. Uncooked vegetables may be important for $H$ pylori infection in Chile, and the possibility of oral transmission has been suggested by PCR demonstration of
$H$ pylori in saliva and dental plaque (42).

\section{SYMPTOMATOLOGY}

Although over half of the world's population is infected with $H$ pylori, the acute illness associated with initial infection is rarely diagnosed. The incubation is approximately one to 10 days and may be associated with epigastric pain, nausea, retching, flatulence and malaise. There is epithelial degeneration and heavy infiltration of PMN in the lamina propria as well as in the surface epithelium and the epithelium lining the pits.

It must be recognized that it is debatable whether $H$ pylori infection alone causes upper gastrointestinal symptoms (43). Chronic H pylori infection may be asymptomatic, or associated with nonspecific symptoms or with symptoms of peptic ulcer disease. In asymptomatic blood donors, 16\% had DU and 5\% had GU on endoscopy, and three of $21 \mathrm{H}$ pylori-positive blood donors had previously unsuspected gastric cancer. Similar findings are evolving from studies performed in Ireland, although to date no gastric cancers have been found (44).

It remains unclear whether asymptomatic individuals with $H$ pylori should be treated. It is controversial whether the $50 \%$ of individuals with nonulcer dyspepsia who are $H$ pylori-positive should be treated. It is also controversial whether clearing of $H$ pylori improves the symptoms in patients with nonulcer dyspepsia, even when $H$ pylori is clear. The answer is uncertain, however, because most studies have followed $H$ pylori-positive symptomatic persons for a short period of time and nonulcer dyspepsia is a remitting disease (45).

\section{NEW DIAGNOSTIC TESTS}

Following $\mathrm{H}$ pylori infection, there is an initial immunoglobulin (Ig) M response followed by $\operatorname{IgG}$ conversion that accompanies the fall in the IgM titres (46). The 'common mucosal system' provides the conceptual framework for understanding the observation that antibody and saliva reflect immune events within the gastric mucosa. A quantitative ELISA assay has been developed to detect antibody in saliva. The demonstration of IgG antibody in saliva correlates with $H$ pylori infection, and the sensitivity and specificity of the test are greater than $90 \% \mathrm{com}$ pared with concomitant serum antibody results. The salivary antibody assay is also highly sensitive and specific compared with direct parameters of infection, and this test may be used to determined conversion from $\mathrm{H}$ pylori-positive to -negative status after eradication therapy (47). Importantly, seven of 35 patients who tested negative for $\mathrm{H}$ pylori by the cod liver oil (CLO) test had a positive saliva test, and the CLO test may be less frequently positive in patients who are tested while there is blood or protein in the stomach. There are other problems with serological diagnosis, including the need for multiple dilutions, and there can be a very slow change in titre after eradication therapy. The cut-off point in the saliva test is crucial and requires further validation (unpublished data).

\section{RECURRENCE AND REINFECTION}

Recurrence of $H$ pylori infection after eradication therapy may be due to recrudescence (failure to eradicate) or true reinfection (48). If eradication is defined as absence of $\mathrm{H}$ pylori four or more weeks after therapy (including absence of clusters of PMN), most subsequent recurrences will be reinfections. The reinfection rate is less than $0.5 \%$ per year in developed countries, but may be more common in developing countries. It is unknown what leads to reinfection. It is possible that in some persons an early reinfection may in fact have been due to a false negative test for $\mathrm{H}$ pylori. For example, because the CLO and urea breath tests require a high density of $\mathrm{H}$ pylori, there may be a false negative rate. Although biopsy demonstration of $\mathrm{H}$ pylori is considered the 'gold standard', it is limited by the need for gastroscopy and the size, location, number and handling of biopsies.

\section{THERAPY}

Predicted antimicrobial effective- 
ness (minimal inhibitory concentration [MIC]) obtained in vitro fails to predict in vivo effectiveness of antihelicobacter therapy (49). MICs are usually higher in an acidic, compared with an alkaline, environment.

It appears unimportant whether antibiotics are taken with meals. Amoxycillin needs to be given by mouth and nonsystemically, and metronidazole, clindamycin, but not amoxycillin, are secreted into the mucosa and lumen of the stomach. When acid secretion is inhibited with ranitidine, amoxycillin concentration in the antral mucosa is actually decreased (50), rather than increased as expected. Uptake of amoxycillin occurs from the gastric lumen,

\section{REFERENCES}

All references are from presentations at an international symposium entitled 'Helicobacter pylori: Basic mechanisms to clinical cure', Ameilia Island, Florida, USA, November 3-6, 1993

1. Fox JG. Animal models of Helicobacter pylori and other gastric helicobacters.

2. Mégrand F. Helicobacter pylori species heterogenicity.

3. Graham DY. Helicobacter pylori and duodenal ulcer disease.

4. Mobley HLT. Helicobacter pylori urease.

5. Shermann PM. Adherence and internalization of epithelial cells by Helicobacter pylori.

6. Lee A. Helicobacter pylori colonisation factors.

7. Sarosiek J, Namiot Z, Marshall BJ, Peura DA, Gurrant RL, McCallum RW. Breakdown of mucous layer by Helicobacter pylori.

8. Szabo S, Kusstatscher S, Nagy L, Sandor S. Mechanisms of ammoniainduced gastric mucosal injury.

9. Northfield TC. Decreased hydrophobicity gastric mucosa due to Helicobacter pylori infection.

10. Dixon MF. Spectrum and implications of inflammation with Helicobacter pylori.

11. Walsh JH, Reeve JR Jr, Anton P, Quismorio D, Territo M. Role of chemotaxis in Helicobacter pylori mucosal damage.

12. Chadwick VS. Helicobacter pylori induced neutrophil activation and production of toxic oxygen radicals.

13. Graham DY. Tight junction destruction and leukocyte trafficking in response to Helicobacter pylori.

14. Lee A. Lipopolysaccharide (LPS) related damage by Helicobacter pylori.

15. Dunn BE, Ilver D, Phadnis SH. Helicobacter pylori $54 \mathrm{KD}$ heat shock protein. with a significant correlation between luminal and tissue concentrations of amoxycillin. The precise mechanism of proton pump synergism with anti-H pylori agents requires further understanding.

Twice-a-day dosing is essential for optimal eradication rates for proton pump inhibitors plus amoxycillin (20 mg bid omeprazole plus $20 \mathrm{~g}$ bid amoxycillin). Adverse effects occur in fewer than $5 \%$ of patients on this regimen, but in over $25 \%$ of patients on triple therapy (51). Amoxycillin as capsules is as good as liquid for eradication of $H$ pylori. It is unclear whether pretreatment with proton pump inhibitors may reduce eradication rates.

16. Salaspuro M. Helicobacter pylori alcohol dehydrogenase.

17. Crabtree JE. Helicobacter pylori vacuolating toxin.

18. Ernst PB, Reyes V, Jin Y, Navarro J, Crowe SE. Overview of the immune response to Helicobacter pylori.

19. Mai UEH. Specific Helicobacter pylori: immune response.

20. Wallace JL, Hogaboam CM, Rioux KP. Gastric mucosal injury: interactions of mast cells, cytokines and nitric oxide.

21. Newell DG, Stacey AR, Hawlin PR. The $\mathrm{B}$ cell immune response to Helicobacter pylori.

22. Croitoru K. Down-regulation of the immune response to Helicobacter pylori.

23. McColl KEL, Ardill JES, El-Omar E. Disturbances of gastrin homeostasis by Helicobacter pylori.

24. Dunn BEH. Role of bacterial amines in Helicobacter pylori-associated hypergastrinemia.

25. Calam J, Moss SF, Tiker N, Legon S. Abnormalities of gastrin and somatostatin in Helicobacter pylori infection.

26. Cave DR. Helicobacter pylori and parietal cell function.

27. Stead RH, Hewlett BR, Lhotak S, Colley ECC, Frendo M, Dixon MF. Do gastric mucosal nerves remodel in Helicobacter pylori gastritis?

28. Axon ATR. The ascorbic acid story.

29. Deusch K. T Cell subsets: responses to Helicobacter pylori.

30. Lechago J. Role of Helicobacter pylori in atrophic gastritis and intestinal metaplasia.

31. Stolte M, Bätz C, Eidt S. 'Hypertrophic' gastritis in Helicobacter pylori infection.

32. Lambert JR. Prevalence/disease correlates of Helicobacter pylori.

33. Correa P. Determinants of gastritis
Failure of double therapy can be followed by another course of double or triple therapy. There may be sanctuary sites in the stomach to prevent successful eradication therapy. The combination of bismuth, metronidazole and tetracycline/amoxycillin gives eradication rates above $80 \%$. Alarm concentrations of bismuth above $50 \mathrm{mg} / \mathrm{L}$ do not occur except in patients with renal failure. Smoking may interfere with triple therapy. Metronidazole resistance occurs in $35 \%$ of patients after the second course of triple therapy. Acquired resistance is also common with clarithromycin. Smoking may interfere with the redox action of metronidazole.

phenotype and chronicity in Helicobacter pylori infection.

34. Wright NA. Evidence for a growth factor secreting cell lineage peptic ulcer disease.

35. Seppälä K. Helicobacter pylori and gastric ulcer disease.

36. Van Zanten SV. Role of NSAIDs and aspirin in Helicobacter pylori infection.

37. Forman D. Significance of the relationship between Helicobacter pylori infection and gastric cancer.

38. Yeomans ND. Role of bacterial overgrowth in carcinogenesis.

39. Wadström T. The role of PCR techniques in the epidemiology of Helicobacter pylori-associated gastric cancer.

40. Stolte M, Eidt S, Fischer R. Helicobacter pylori associated gastric lymphoma.

41. Sipponen P. Long-term consequences of Helicobacter pylori infection.

42. Hazell SL. Helicobacter pylori in developing countries.

43. Marshall BJ, Nguyen T, Schorling J, Paskell S. Helicobacter pylori in a general medical clinic: Commonplace but no associated with disease states.

44. O'Morain C. Helicobacter pylori in asymptomatic people.

45. Talley NJ. Helicobacter pylori and functional dyspepsia.

46. Axon ATR. Acute infection with Helicobacter pylori.

47. Clancy R, Cripps A, Webster V, Taylor D, McShane L. Detection of antibody in saliva as an aid to management in Helicobacter pylori infection.

48. Graham DY. Risk of reinfection with Helicobacter pylori.

49. Graham DY. Determinants of antibiotic effect.

50. Lambert JR. Mucosal antibiotic levels.

51. Tytgat GNJ. Basic overview of result of eradication therapy for Helicobacter pylori. 


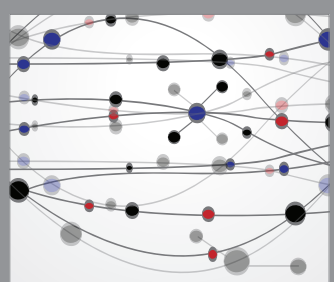

The Scientific World Journal
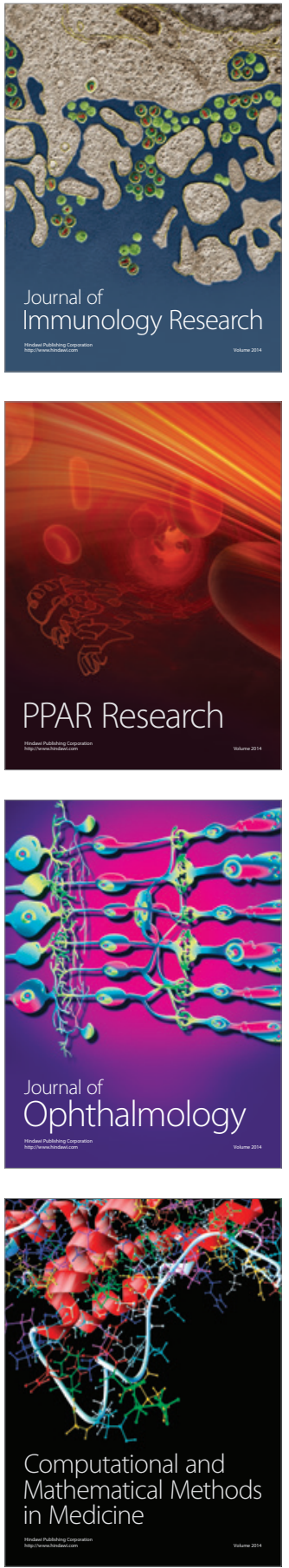

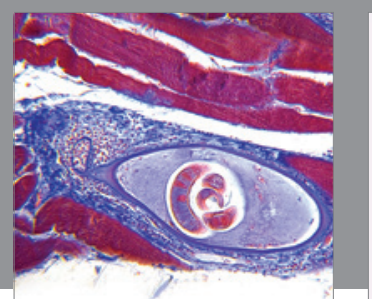

Gastroenterology Research and Practice

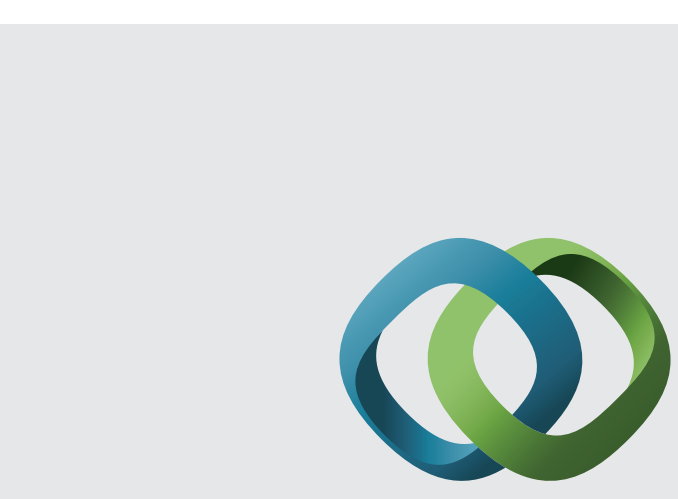

\section{Hindawi}

Submit your manuscripts at

http://www.hindawi.com
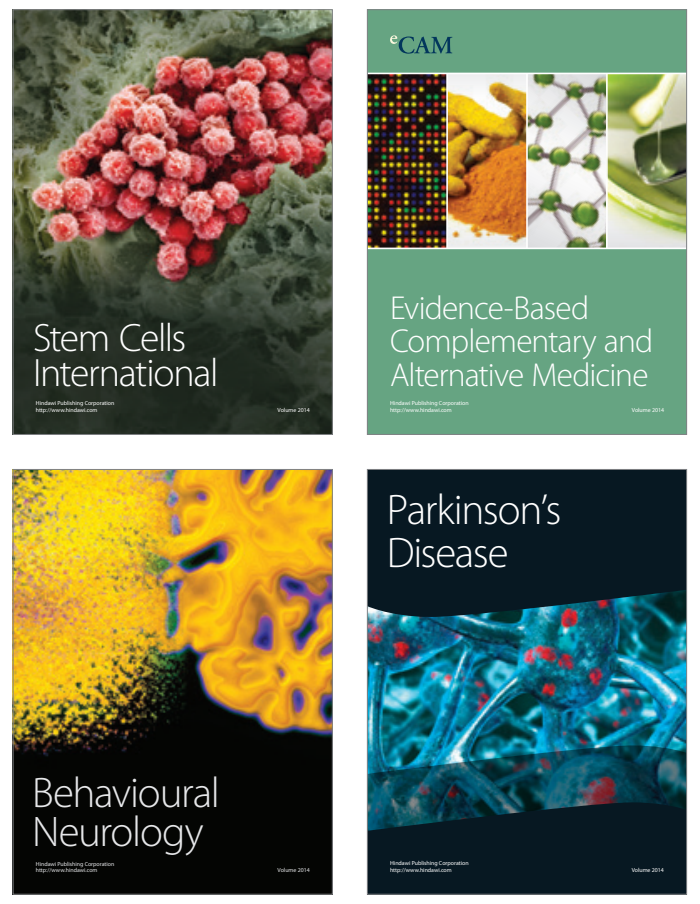
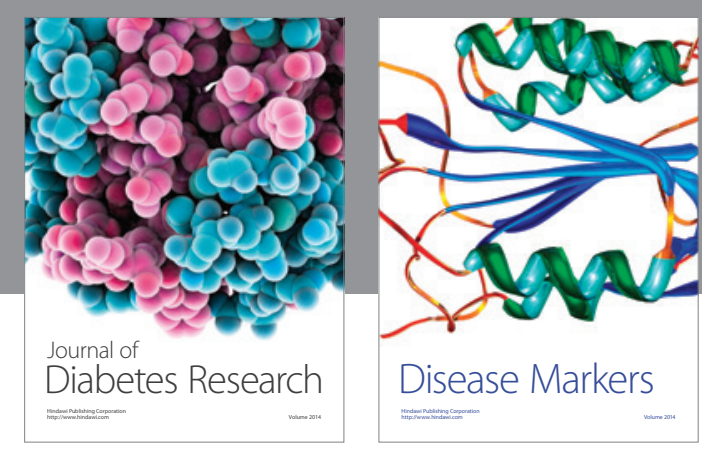

Disease Markers
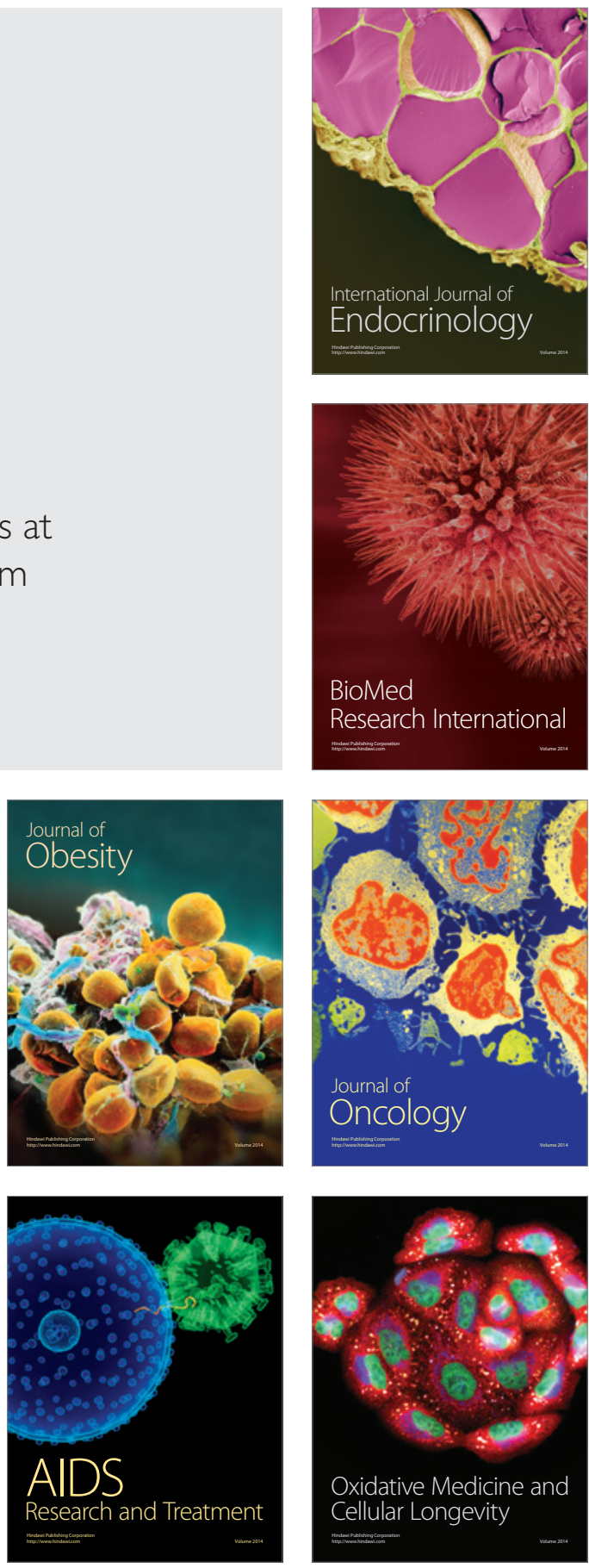